Research Paper

\title{
Lethal effects of a Mexican Beauveria bassiana (Balsamo) strain against Meccus pallidipennis (Stal)
}

\author{
Zumaquero Rios José Lino ${ }^{1}$, López-Tlacomulco José Juventino ${ }^{1}$, \\ Rojas García Raúl ${ }^{1}$, Sansinenea Estibaliz ${ }^{2}$ \\ ${ }^{1}$ Laboratorio de Parasitología y Vectores, Escuela de Biología, \\ Universidad Autónoma de Puebla, Puebla, México. \\ ${ }^{2}$ Facultad de Ciencias Químicas, Universidad Autónoma de Puebla, Puebla, México.
}

Submitted: March 4, 2013; Approved: September 9, 2013.

\begin{abstract}
The entomopathogenic fungus Beauveria bassiana (Balsamo 1835) Vuillemin is an effective alternative control agent against some agricultural pests and biological vectors of important diseases such as Chagas disease. In this work we studied an isolate of Beauveria bassiana from of the town of San Antonio Rayón, Puebla, Mexico and its entomopathogenic effects on Meccus pallidipennis (Stal 1872). Phylogenetic analysis using molecular comparison of the ITS and EF1 $\alpha$ genes, showed that the resulting cladogram places the BUAP 04 strain with a relationship closer to the AFAO 9-6 strain, within the diversity of the $B$. bassiana sensu lato group. Although there was the possibility that BUAP 04 strain was a direct descendant of strains used in campaigns of biologic control, molecular study allowed us to recognize that it was a different fungus due to numerous inserts. A strain isolated from a $T$. dimiata was evaluated for pathogenicity against another triatoma (Meccus pallidipennis) species obtaining an $\mathrm{LC}_{50}$ of $4.16 \times 10^{6}$ spores $/ \mathrm{mL}$, confirming that the BUAP 04 strain is virulent for M. pallidipennis and could be a good prospect for formulations to control M. pallidipennis.
\end{abstract}

Key words: Chagas disease, biocontrol agent, triatomines.

\section{Introduction}

Chagas disease is a major parasitic disease, caused by Trypanosoma cruzi and is transmitted to mammalian hosts by several species of hematophagous triatomines. Chagas disease is given little public health priority in Mexico, despite ample clinical evidence of its importance (Guzmán-Bracho, 2001). In México, at least 33 species of triatomines are known, of which 23 are unrecorded from other countries (Salazar-Schettino et al., 2010; Martinez-Ibarra et al., 2011). Among them, Meccus (former Triatoma) pallidipennis (Stal, 1872), a peridomestic vector, is considered one of the most important vectors of Chagas disease in Mexico (Martinez-Ibarra et al., 2009) because it usually has high entomological indexes and it occurs in houses and chicken roosts in villages of 11 states (33\%) of central, southern, eastern and western Mexico (Martinez-Ibarra et al., 2009; Martinez-Ibarra et al., 2011).
Biological control agents are preferred against these disease vectors. Among alternative control tools, entomopathogenic fungi are known pathogens of some triatomines (Luz and Batagin 2005; Pedrini et al. 2009; Safavi, 2010) . However, due to the great diversity of triatomine vectors in Mexico, it is necessary to find new entomopathogenic Beauveria strains with lethal effects to different triatomines.

Entomopathogenic fungi are among the natural enemies of pests in agroecosystems associated with soil and are distributed around the world (Meyling et al., 2012). The entomopathogenic fungus Beauveria bassiana (Balsamo, 1835) Vuillemin is a capable alternative control agent against some agricultural pests and biological vectors of important diseases such as Chagas disease (Luz and Batagin 2005; Pedrini et al. 2009; Safavi, 2010). Species recognition in Beauveria is difficult due to a lack of taxonomically informative morphology. A molecular phylo-

Send correspondence to Sansinenea Estibaliz. Facultad de Ciencias Químicas, Universidad Autónoma de Puebla, Ave San Claudio s/n, Edificio 76, Ciudad Universitaria Col San Manuel, 72570 Puebla, México. E-mail: estisan@yahoo.com, linozuma@hotmail.com. 
genetic analysis, based on nuclear ribosomal internal transcribed spacer (ITS) and elongation factor 1-alpha $(E F 1-\alpha)$ sequences for isolates from diverse geographic origins, habitats and insect hosts, was used to resolve six well supported clades within Beauveria bassiana Vuillemin (Rehner and Buckley, 2005; Garrido-Jurado et al., 2011).

A fungal isolate collected from a bug in a rural community in the state of Puebla, Mexico, yielded a strain that was aggressive against specimens of a controlled breeding of triatomines. Controlled development of this strain, called BUAP 04, showed morphological variations of color and colonization with respect of two reference strains AFAO 9-1 and AFAO 9-6, certified by the National Center for biological control. This fungus was aggressive in laboratory bioassays against specimens of a controlled breeding of triatomines.

Therefore in this work, we determined the morphology of this strain, phylogenetic affinities and its effect on mortality of Meccus pallidipennis (Stal, 1872). M. pallidipennis is considered one of the most important vectors of Chagas in the southern of Mexico (Martinez-Ibarra et al., 2010; Martinez-Ibarra et al., 2011), and is found in domestic and peridomestic habitats in the south of State of Puebla where there have been high rates of human infection with Trypanosoma cruzi ( Zumaquero-Rios et al., 2001; Sandoval-Ruiz et al., 2008).

\section{Materials and Methods}

\section{Fungus isolation and morphological identification}

The fungus of this study, called BUAP 04, was isolated from a dead specimen of Triatoma dimidiata in San Antonio Rayón locality of Puebla State, Mexico (20 $0^{\circ} 14^{\prime} 08$ $\mathrm{N}$ y $\left.97^{\circ} 45^{\prime} 00^{\prime \prime} \mathrm{W}\right)$. This strain was grown on SDA medium (Sabouraud-Dextrose- Agar) with $0.01 \%$ of ampicillin and incubated at $28{ }^{\circ} \mathrm{C}$. The macroscopic identification of BUAP 04 was performed using the keys of Heale et al. (1989). Microscopic identification of the strains was based on previously reported characterization (Goettel, 1984, 1997). The reference strains, AFAO 9-1 and AFAO 9-6, certified by the National Center for biological control, were selected because they were the strains used for biological purposes to control Hypothenemus hampei (coffee berry borer) and there was a need to compare the new isolate with those used in the region as agents of biological control. BUAP 04 was compared with morphological characteristics (macroscopic and microscopic) of the reference strains grown in the same conditions.

\section{Molecular identification}

BUAP 04, and reference strains, AFAO 9-1 and AFAO 9-6, were grown on PDB (Potato-dextrose-Broth) medium until the optical density reached D. $\mathrm{O}_{600}=1$. The cells were recovered by centrifugation and then DNA was extracted following the method described by Sherman et al
(1986). The quantity of DNA was verified in an agarose gel at $0.8 \%$ by electrophoresis. Two genes were amplified by PCR (ITS and EF1-alpha) of the three fungal strains using a touchdown PCR procedure (Don et al., 1991). The ITS ( 600 bp segment) was amplified and sequenced with ITS5 (5-GGAAGTAAAAGTCGTAACAAGG-3) and ITS4 (5-TCCTCCGCTTATTGATATGC-3) primers and EF1- $\alpha$ ( $\sim 1200$ bp segment) was amplified and sequenced using EF1T (5-ATGGGTAAGGARGACAAGAC-3) and 1567R (5-ACHGTRCCRATACCACCSATCTT-3) primers using the conditions described by Rehner and Buckley (2005). PCR amplifications were performed in a total volume of 50 $\mu \mathrm{L}$ using an Eppendorf 500W/Mastercycler thermocycler and Platinum ${ }^{\circledR} P f x$ polymerase according to the instructions of the supplier (INVITROGEN). The amplified fragments were sequenced in the Centro de Investigación y Estudios Avanzados (CINVESTAV) of Irapuato. The sequence data were deposited in GenBank. The sequences of 24 taxa representing each clade basal phylogenetic analysis relevant Rehner and Buckley (2005), available in Genbank, were recovered. The sequences of Cordyceps scarabaeicola, which was selected as outgroup, were included. In the alignment, $600 \mathrm{bp}$ of ITS and $1200 \mathrm{pb}$, which correspond to the coding region of ITS and EF1- $\alpha$ respectively, were used. Using the Clustal W program (Thompson et al., 1997), a maximum parsimony analysis was made on the MEGA program (Tamura et al., 2011). The phylogenetic analysis consisted of 500 replicas of heuristic searches for each gene. A single array with both gene sequences was then analyzed and the resulting cladograms of 500 replicas of heuristic search were obtained. A strategy, of supporting bootstrap with 1000 replicas that was recovered in the strict consensus tree, was implemented.

\section{Evaluation on Meccus pallidipennis}

For the virulence test, strain BUAP 04 was grown on petri dish with PDA at $28{ }^{\circ} \mathrm{C}$ during 20 days and then the spores were recovered with TWEEN $800.01 \%$. The concentration of the spores was calculated by the counting in Neubauer camera and the viability of spores was determined by trypan blue exclusion method (Strober, 2001). From an initial concentration of $1 \times 10^{7}$ spores $/ \mathrm{mL}$ of strain BUAP 04, seven dilutions were performed $\left(9 \times 10^{6}, 7.5 \times 10^{6}\right.$, $7 \times 10^{6}, 4 \times 10^{6}, 2 \times 10^{6}, 1 \times 10^{6}, 5 \times 10^{5}$ spores $/ \mathrm{mL}$ ) and were sprayed on each group of bugs (Luz et al., 2004). 1075 specimens of fifth stage of Meccus pallidipennis were obtained from a colony established in laboratory conditions which were sprayed with a solution of sodium hypochlorite at $0.2 \%$ to prevent a possible infection by bacteria and other fungi. The experimental design consisted of five repetitions and a control group by dilution. Each experimental unit was formed of 25 specimens within a black plastic bottle of 500 $\mathrm{mL}$, where organisms were sprayed with $2 \mathrm{~mL}$ of the corresponding dilution and controls were sprayed with the same 
volume of sterile distilled water. Once treated, the specimens were returned to strict conditions of lighting (dark containers with folded surface), photoperiod (light source exposure two hours per week), temperature $\left(25^{\circ} \mathrm{C}\right)$ and relative humidity (60\%) (Luz et al., 1998b). Mortality of the specimens was recorded 96 hours after the application of dilutions and until 25 days, that ended the experiment. Using the Probit 1.5 program (EPA, 2012) $\mathrm{LC}_{50}$ and $\mathrm{LC}_{90}$ were determined, and compared with previous results obtained for the strains AFAO (Zumaquero-Rios et al., 2005). All organisms that died during the experiment were placed in Petri dishes with wet and sterile filter paper to highlight the emergence of the fungus. The emergent fungus (Figure 1) was reseeded in Petri dishes with PDA medium to corroborate morphological characteristics of the isolate. Using Fisher's exact test, an ANOVA was performed to compare the average mortality for the total number of repetitions of each of the eight treatments $(p=0.05)$.

\section{Results}

\section{Morphological characteristics}

The BUAP 04 and AFAO 9-6 strains showed a colony diameter average of $8 \mathrm{~mm}$ at eight days, a dusty appearance and cream-color, which differed in comparison to the growth diameter of $10 \mathrm{~mm}$, cottony texture and lighter cream color of the strain AFAO 9-1. In the microscopic observation of BUAP 04 and AFAO 9-6 strains, short hyphae, hyaline, simple and septate were highlighted; simple conidiophores grown as irregular shape, composed of clusters of conidiogenous cells in bottle shape; sterigma in zig-zag with large amount of globose spores with a diameter of $2.4 \mu \mathrm{m}$ approximately. In comparison, the strain AFAO 9-1 developed long hyphae, hyaline, simple and septate with fewer conidiophores and conidiogenous cells but with the same characteristics of sterigma and the same shape and size of the spores of isolate strain.

\section{Molecular and phylogenetic analysis}

From molecular amplification of the reference (AFAO 9-1 and AFAO 9-6) and BUAP 04 strains, fragments of $600 \mathrm{bp}$ of the ITS gene and $1200 \mathrm{bp}$ for the EF1- $\alpha$ gene were obtained, which were verified by agarose gel electrophoresis using DNA molecular weight markers (1 kb plus, Invitrogen).

The amplified fragments of ITS and EF1- $\alpha$ genes were sequenced and were deposited in GenBank (Access numbers: JX284408 (BUAP 04), JX284409 (AFAO 9-1) and JX284410 (AFAO 9-6) for ITS sequences and JX495611 (BUAP 04), JX495612 (AFAO 9-1) and JX495613 (AFAO 9-6) for EF1- $\alpha$ sequences. The alignment of the ITS and EF1- $\alpha$ genes sequences showed high similarity ( 99.5 and 99 respectively) with B. bassiana sensu lato genes. In the alignment of the EF1- $\alpha$ fragment four exons (of 45, 27, 63 and $648 \mathrm{pb}$ encoding a 261 aa partial protein) were found by comparison to cDNA sequences taken from 24 strains. These exons were highly conserved and that mutations of the genomic PCR fragments were mainly in the introns.

Both the ITS and EF1- $\alpha$ sequences of the Mexican strains remained in close phylogenetic relationship with Brazilian strains as a result of a polytomy between these strains (cladograms not shown). From phylogenetic analysis of the matrix composed of the two gene sequences, two trees of 263 steps, $C I=0.73$ and $\mathrm{RI}=79$ were produced. In this analysis, BUAP 04 always formed a monophyletic

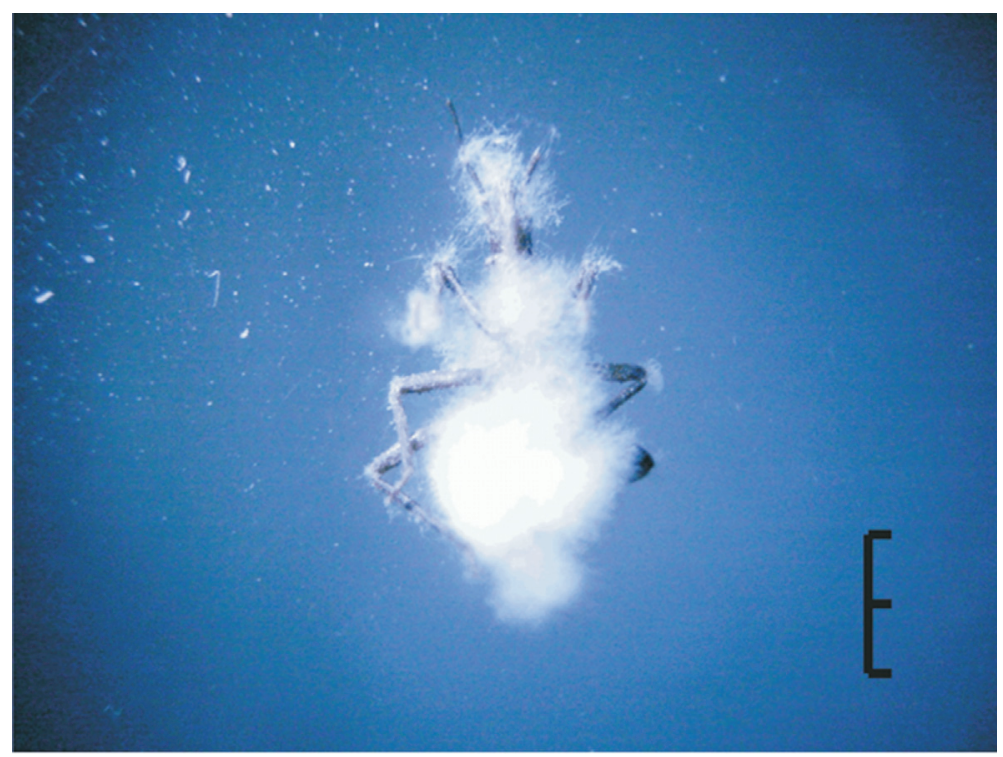

Figure 1 - Beauveria bassiana emerging through the coaxes and spiracles from Meccus pallidipennis. 


\begin{tabular}{|c|c|c|c|c|c|}
\hline \multirow{2}{*}{ Tree consensus } & \multirow{2}{*}{ Isolated } & \multirow{2}{*}{ Country } & \multicolumn{2}{|c|}{ No. Access } & \multirow{2}{*}{ Beauveria $s p$. } \\
\hline & & & ITS & EFI $\alpha$ & \\
\hline & *BUAP 04 & MEXICO & JX284408 & JX495611 - & \\
\hline & *AFAO 9-6 & MEXICO & JX284410 & JX495613 & \\
\hline & *AFAO 9-1 & MEXICO & JX284409 & JX495612 & \\
\hline & 1959 & BRAZIL & AY531997 & AY531906 & \\
\hline & 0753 & BRAZIL & AY532046 & AY531955 & \\
\hline & 1053 & BRAZIL & AY531974 & AY531883 & \\
\hline & 0842 & COLOMBIA & AY532054 & AY531963 & \\
\hline & 1558 & ITALY & AY531984 & AY531893 & \\
\hline & 1829 & BRAZIL & AY531993 & AY531902 & - bassiana s. 1 . \\
\hline & 6721 & COREA & AY532034 & AY531943 & \\
\hline & 0937 & BRAZIL & AY532056 & AY531965 & \\
\hline & 0296 & USA & AY532013 & AY531922 & \\
\hline & 0714 & CHINA & AY532042 & AY531951 & \\
\hline & 0300 & AUSTRALIA & AY532015 & AY531924 & \\
\hline & 1478 & BRAZIL & AY531981 & AY531890 & \\
\hline & 2579 & USA & AY532007 & AY531916 & \\
\hline & 1848 & BELGIUM & AY531995 & AY531904- & \\
\hline & 4362 & JAPAN & AY532025 & AY531934 & \\
\hline & 4474 & CHINA & AY532027 & AY531936 & \\
\hline & 2544 & MEXICO & AY532005 & AY531914 & \\
\hline & 2857 & MEXICO & AY532009 & AY531918 & - fc. bassiana \\
\hline & 0292 & RUMANIA & AY532011 & AY531921 & \\
\hline & 2054 & USA & AY532002 & AY531911 & \\
\hline & 292 & CHILE & AY532012 & AY531920- & - vermiconia \\
\hline & 1685 & JAPAN & AY531990 & AY531899- & - scarabaeicola \\
\hline & 1969 & PERU & AY531998 & AY531907 & \\
\hline & 2641 & BRAZIL & AY532008 & AY531917 & - amorpha \\
\hline & EFC2533 & COREA & AY532058 & AY531967 & \\
\hline
\end{tabular}

Figure 2 - Tree of strict consensus, showing the phylogenetic relationships of the isolate BUAP04 and other strains of Beauveria isolated from different countries. The terminal numbers correspond to sequences of reference of Rehner and Buckley, (2005). * The asterisk indicates the sequences resulted of this work.

group with AFAO reference strains. In this topology, BUAP 04 and AFAO 9-6 were nested as sister units. This group is nested in a polytomy within which we observe the monophyletic group of three Brazilian strains. The isolate and reference strains appear as one of the monophyletic derived nested group within an ancient general node, in a similar topology to that found by Rehner \& Buckley (2005) that defines the group of B. bassiana s.l. (sensu lato), as shown in Figure 2.

\section{Lethal concentrations}

The $\mathrm{LC}_{50}$ of the BUAP 04 isolate was determined to be $4.16 \times 10^{6}$ spores $/ \mathrm{mL}$ and the $\mathrm{LC}_{90}$ was shown to be $1.71 \times 10^{7}$ spores $/ \mathrm{mL}$. The trypan blue staining test was negative in all cases proving that all the spores were viable. The percentage of clear mycosis in dead individuals was around 50\% (Figure 3). High concentrations showed a greater external infection (last three concentrations). Living individuals were recovered from all tested dilutions and in some specimens subjected to lower dilutions no obvious mycosis was observed. The isolate apparently caused the infertility of eggs of the surviving females of all doses.

\section{Statistical comparison of treatments}

The analysis of variance (ANOVA) showed that there are significant differences in the recorded mortality in three ranges of spore concentration (Figure 4) though it is worth mentioning that the dilution $7 \times 10^{6}$ spores $/ \mathrm{mL}$ did not present significant differences from groups two and three.

\section{Discussion}

The characteristics of BUAP 04 strain identified it as Beauveria bassiana (Goettel, 1984, 1997; Heale et al., 1989). The morphological features of conidia are common 


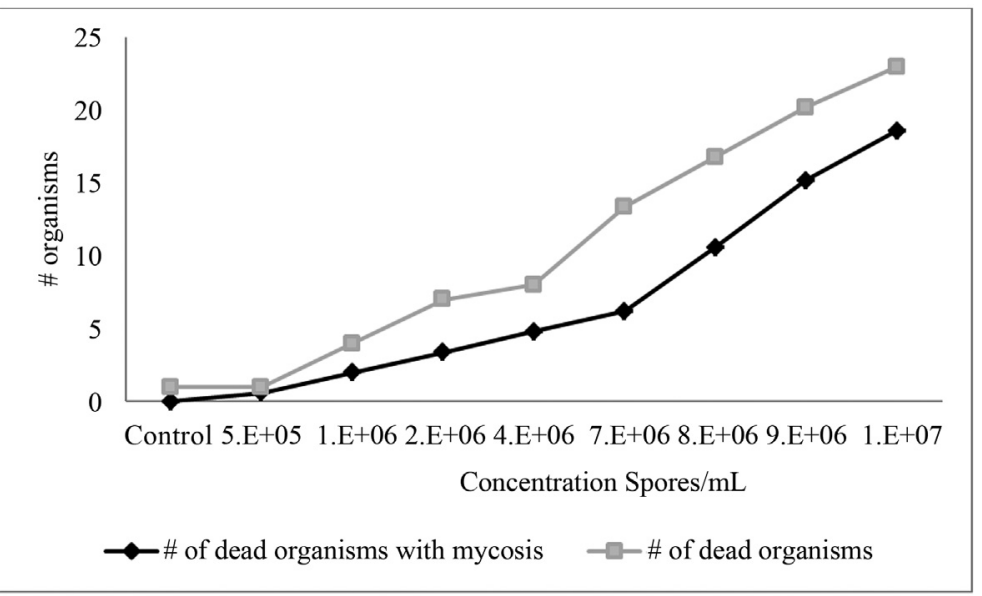

Figure 3 - Evaluation of BUAP 04 strain on Meccus Pallidipennis. The figure shows the number of dead organisms and dead organisms with mycosis after treatment with BUAP 04.

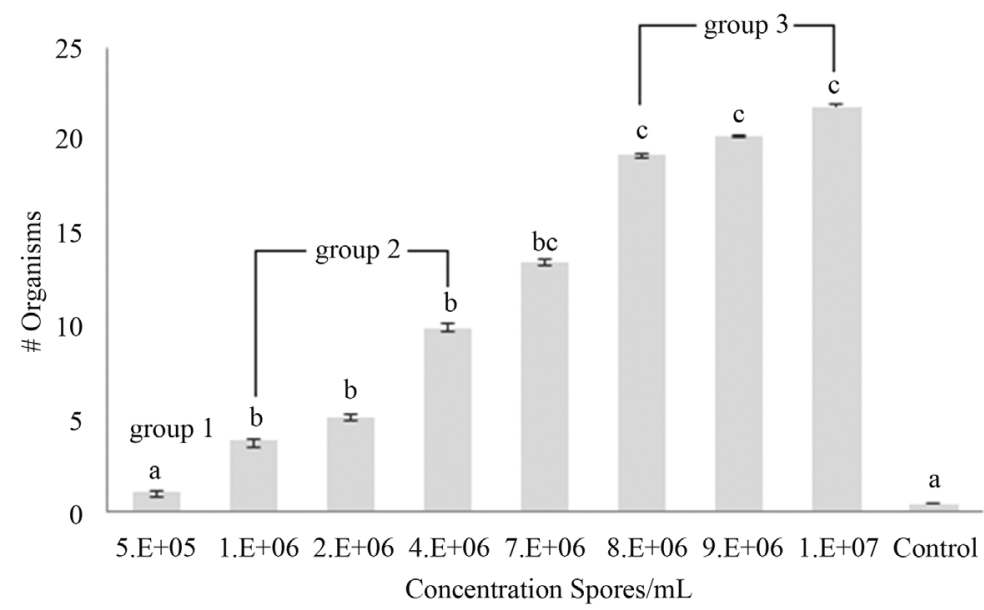

Figure 4 - Number of dead specimens of Meccus pallidipennis ( $\mathrm{bar}=$ average \pm standard error) for the isolate BUAP 04 in each treatment. The same letter above the bar indicates that there is no significant difference within the group.

tools for identification in Beauveria. Morphological and molecular studies have shown that the broad patterns of diversity in Beauveria have been accurately predicted in previous morphological studies. However, they have also shown that these approaches are insufficient to investigate species such as B. bassiana (Rehner and Buckley, 2005). Phylogenetic analysis of the sequences of EF1-a resulted in cladograms with higher resolution, consistent with the results of Rehner and Buckley (2005) and Garrido-Jurado et al(2011). The resulting topologies of phylogenetic analyses of sequences of the ITS and EF1- $\alpha$ genes separately, were highly similar to the topologies obtained by Rehner and Buckley (2005). Our cladogram of consensus, obtained from the analysis of both genes, matches with the characterization of $B$. bassiana sensu lato group. In this sense, the resulting cladogram allows us to identify the BUAP 04 isolate with relations closer to the AFAO 9-6 strain, within the diversity of the B. bassiana s.l. group. Although there was the possibility that the BUAP 04 isolate was direct de- scendant of strains distributed throughout the campaigns of biologic control, molecular study allowed us to recognize that it was a different fungus due to the numerous inserts that are present. Information obtained from the cladogram of our work, highlights the phylogenetic proximity of the BUAP 04 isolate with strain AFAO 9-6, which shows similar morphological characteristics in the development of its cultures, as shown by the comparative morphology of the isolate.

Natural mortality in the control group corresponds to the expected since biologic cycle studies previously reported a low mortality for the fifth stage (Martinez-Ibarra $e t$ $a l ., 2009)$. The survivors of the group in totality were transformed into healthy imagos, which in addition to the null expression of mycosis, discards the fungal contamination of dead specimens during treatment. It was proven that BUAP 04 isolate is virulent for Meccus pallidipennis.

The $\mathrm{LC}_{50}$ was similar to that obtained by Luz et al. (1998) for Metarhizium anisopliae, which corresponds to a 
concentration of spores higher than the corresponding value for $B$. bassiana in this study. Our data were similar to those obtained by Lecuona et al. (2001) who recorded $\mathrm{LC}_{50}$ in a range of $5.3 \times 10^{6}$ to $11.5 \times 10^{6}$ spores $/ \mathrm{mL}$ in a period of two weeks upon infection of $T$. infestans. It can be proved that in concentrations with highest number of spores the mortality is increased in less time and the percentage of specimens that develop external mycosis is also higher. We suggest an analysis of the $\mathrm{LC}_{50}$ over a longer period because, in general, few spores are required to increase mortality, to affect its ability to fertilize eggs and cause damage that suppresses feeding as was observed in the conduct of survivor specimens. The evaluation studies of the AFAO 9-1 and AFAO 9-6 strains, report a higher $\mathrm{LC}_{50}$ than obtained with BUAP 04 strain, and a smaller mortality percentage at low dilutions, confirming that this strain could be a good candidate for formulations to control $M$. pallidipennis (Zumaquero-Rios et al., 2005).

The observation of sporulation of the fungus in dead specimens that were treated with low concentrations, evidenced the development of massive internal hyphae that generate all known pathogenic actions on the digestive system and the reproductive tract of the insect, targets recognized in other studies where infection included ovarioles, spermatheca, and other bodies (Zumaquero and Moran unpublished data).

\section{Acknowledgments}

The authors acknowledge VIEP (Project NAT-I-97) for financial support. We want to give a special acknowledgement to Dr. Ernest Schnepf for proofreading the manuscript improving it.

\section{References}

Don RH, Cox PT, Wainwright BJ, Baker K, Mattick JS (1991) 'Touchdown' PCR to circumvent spurious priming during gene amplification. Nucleic Acids Res 19:4008.

EPA (2012) (Environmental Pollution Agency), p. Provit, Ecological Monitoring Research, Division Environmental Monitoring Systems Laboratory. 15 edition. Cincinnati,Ohio, US.

Garrido-Jurado I, Marquez M, Ortiz-Urquiza A, Santiago-Alvarez C, Iturriaga EA, Quesada-Moraga E, Monte E, Hermosa R (2011) Genetic analyses place most Spanish isolates of Beauveria bassiana in a molecular group with word-wide distribution. BMC Microbiol 11:84.

Goettel MS (1984) A simple method for mass culturing entomopathogenic Hyphomycete fungi. Microbiol. Methods 3:1520.

Goettel MS (1997) Fungi: Hyphomycetes, In: Lacey L.A. (ed) Manual of Tencniques in insect Pathology. E:U, pp 213-249.

Guzmán-Bracho C (2001) Epidemiology of Chagas disease in Mexico: An update. Trends Parasitol 17:372-376.
Heale JB, Isaac JE, Chandle D (1989) Prospects for strain improvement in entomopathogenic fungi. Pesticide Science 26:79-92.

Lecuona RE, Edelstein JD, Berretta MF, La Rossa FR, Arcas JA (2001) Evaluation of Beauveria bassiana (hyphomycetes) strains as potential agents for control of Triatoma infestans (Hemiptera: Reduviidae). J Med Entomol 38:172-179.

Luz C, Batagin I (2005) Potential of oil-based formulations of Beauveria bassiana to control Triatoma infestans. Mycopathologia 160:51-62.

Luz C, Rocha LF, Nery GV, Magalhaes BP, Tigano MS (2004) Activity of oil-formulated Beauveria bassiana against Triatoma sordida in peridomestic areas in Central Brazil. Mem. Inst Oswaldo Cruz 99:211-218.

Luz C, Silva IG, Cordeiro CM, Tigano MS (1998) Beauveria bassiana (Hyphomycetes) as a possible agent for biological control of Chagas disease vectors. J Med Entomol 35:977979.

Luz C, Tigano MS, Silva IG, Cordeiro CM, Aljanabi SM (1998) Selection of Beauveria bassiana and Metarhizium anisopliae isolates to control Triatoma infestans. Mem Inst Oswaldo Cruz 93:839-846.

Martinez-Ibarra JA, Martinez-Hernandez F, Villalobos G, Vences-Blanco MO, Salazar-Schettino PM (2010) Update on the distribution of Triatoma bolivari and Triatoma brailovskyi (Hemiptera: Reduviidae: Triatominae) in western Mexico. J Vector Ecol 35:432-434.

Martinez-Ibarra JA, Salazar-Schettino PM, Nogueda-Torres B, Vences MO, Tapia-Gonzalez JM, Espinoza-Gutierrez B (2009) Occurrence of hybrids and laboratory evidence of fertility among three species of the Phyllosoma complex (Hemiptera: Reduviidae) in Mexico. Mem Inst Oswaldo Cruz 104:1125-1131.

Martinez-Ibarra JA, Valencia-Navarro I, Leon-Saucedo S, Ibanez-Cervantes G, Bustos-Saldana R, Montanez-Valdez OD, Cervantes Diaz OI, Nogueda-Torres B (2011) Distribution and infection of triatomines (Hemiptera, Reduviidae) by Trypanosoma cruzi in the state of Michoacan, Mexico. Mem. Inst Oswaldo Cruz 106:445-450.

Meyling NV, Pilz C, Keller S, Widmer F, Enkerli JR (2012) Diversity of Beauveria spp. isolates from pollen beetles Meligethes aeneus in Switzerland. J Invertebr Pathol 109:76-82.

Pedrini N, Mijailovsky SJ, Girotti JR, Stariolo R, Cardozo RM, Gentile A, Juarez MP (2009) Control of pyrethroid-resistant Chagas disease vectors with entomopathogenic fungi. PLoS neglected tropical diseases 3:e434.

Rehner SA, Buckley E (2005) A Beauveria phylogeny inferred from nuclear ITS and EF1-alpha sequences: evidence for cryptic diversification and links to Cordyceps teleomorphs. Mycologia 97:84-98.

Safavi S (2010) Isolation, Identification and Pathogenicity Assessment of a new Isolate of Entomopathogenic Fungus, Beauveria Bassiana in Iran. J Plant Protect Res 50:158-163

Salazar-Schettino PM, Rojas-Wastavino GE, Cabrera- Bravo M, Bucio-Torres MI, Martínez Ibarra JA, Monroy-Escobar MC, Rodas Retana A, Guevara Gómez Y, Vences Blanco MO, Ruiz Hernández AL, Torres Gutiérrez E (2010) Revisión de 13 especies de la familia Triatominae (Hemiptera: 
Reduviidae) vectores de la enfermedad de Chagas en México. J Selv And Res Soc 1:57-80.

Sandoval-Ruiz CA, Zumaquero-Rios JL, Rojas-Soto OR (2008) Predicting geographic and ecological distributions of triatomine species in the southern Mexican state of Puebla using ecological niche modeling. J Med Entomol 45:540-546.

Sherman F, Fink GR, Hicks J (1986) Methods in Yeast Genetics: A Laboratory Course. Cold Spring Harbor Laboratory Press, New York.

Strober W (2001) Trypan Blue Exclusion Test of Cell Viability, Current Protocols in Immunology. John Wiley \& Sons, Inc.

Tamura K, Peterson D, Peterson N, Stecher G, Nei M, Kumar S (2011) MEGA5: Molecular Evolutionary Genetics Analysis Using Maximum Likelihood, Evolutionary Distance, and
Maximum Parsimony Methods. Mol Biol Evol 28:27312739.

Thompson JD, Gibson TJ, Plewniak F, Jeanmougin F, Higgins DG (1997) The CLUSTAL_X windows interface: flexible strategies for multiple sequence alignment aided by quality analysis tools. Nucleic Acids Res 25:4876-4882.

Zumaquero-Rios JL, Valerdi-Minor G, Cid Y (2001) Triatominos en la mixteca poblana de (Xayacatlán de Bravo) Puebla. XXXVI National meeting of entomology proceedings, $p p$ 126-131.

Zumaquero-Rios JL, Saa-Barona O, Martínez-Ortiz P (2005) Evaluation of a bioinsecticide formulated with Metarhizium anisopliae and Beauveria bassiana for the control of vector of the Chagas disease. Entomologia Mexicana 4:991-994.

All the content of the journal, except where otherwise noted, is licensed under a Creative Commons License CC BY-NC. 